\title{
Follower Attributes: Perceptions of Leadership and Followership Experts in the United States
}

\author{
Evgenia V. Prilipko \\ Texas State University
}

This study identifies the most important characteristics of followers as perceived by followership and leadership experts in the United States. The grounded theory constructed as a result of the study reveals that (a) scarcity of followership courses in academic curricula can be explained by the negative stereotype of the term follower prevalent in the Western society, (b) follower skills can be taught, (c) followership should be taught every time leadership is taught at academic levels ranging from high school to post graduate, and (d) 17 follower attributes are suggested for the purpose of teaching individuals.

\section{INTRODUCTION}

Bifurcation between the amount of literature on leadership and that on followership is the most dramatic flaw in the leadership studies (Burns, 1978). While the concept of leadership has been widely researched for decades, followership, as its vital component, has been given scant attention until recently. The last several years, in particular, are marked by a focused attention to various aspects of followership (Malakyan, 2014; Uhl-Bien, Riggio, Lowe, \& Carsten, 2014). Nevertheless, despite various evolving perspectives on followership, scholars are "just scratching the surface of a true understanding of the role that followers play in leadership and in understanding the dynamics of the leader-follower equation" (Riggio, Chaleff, \& Lipman-Blumen, 2008, p. 254).

Historically, the common portrayal of leaders and followers as fixed roles is rooted in the industrial age. While leaders are portrayed with fame, heroism, and superhuman qualities almost to extent of elitism, followers are most commonly described as flaccid, manipulable, and indiscrete masses of voiceless wooden soldiers marching to commands. Kelley (1992) concludes that the negative stereotype of followership is firmly embedded in Western society. Chaleff (2009) affirms that the term follower is associated with images of "docility, conformity, weakness, and failure to excel" (p. 3).

An impressive number of workshops, training sessions, and courses are offered on cultivating leadership skills, corresponding to Gardner's (1987) belief that $90 \%$ of leadership can be taught. However, emphasis on teaching the followership component of the leadership process is very slim. While the first course on followership was offered at Carnegie-Mellon University by Robert Kelley in 1985 (Kelley, 1992, p. 36), availability of such courses at other universities in the United States to this day remains limited.

Although followership has been addressed from various angles, the following questions have not received clear answers in the literature: (a) Can follower skills be taught? (b) What skills need to be 
taught to individuals to enhance their follower skills in the leadership process? (c) At what academic levels should follower skills be taught? Therefore, a critical need exists to examine the teachability of follower skills. Thus, the purpose of this study is to identify the most important characteristics to be exhibited by individuals in the follower role and propose a method of teaching them to become skilled followers.

\section{THEORETICAL FRAMEWORK}

A list of follower attributes proposed by Antelo, Henderson, and St. Clair (2010) is used for the purpose of this study as a theoretical underpinning. The scholars researched the attributes that individuals should exhibit as followers engaged in the leadership process, and proposed the list of 12 follower attributes: Interpersonal relations, group relations, tolerance, conceptual understanding, learning and embracing change, effective communication, reliability as a group member, contribution to the group, emotional intelligence, supporting others, flexibility, and motivation. This theoretical framework served as a platform for the interview protocol. The participants of the study were asked to comment on the importance of each attribute.

\section{POPULATION AND SAMPLE}

The principle of purposive sampling (Hesse-Biber \& Leavy, 2006) was applied to selecting subjects for this qualitative study. A sample chosen for the study represents information-rich cases. "Informationrich cases [emphasis in original] are those from which one can learn a great deal about issues of central importance to the purpose of the research, thus the term purposeful [emphasis in original] sampling" (Patton, 1990, p. 169). Therefore, seven leadership and followership experts from the United States were chosen to be interviewed for the study: Ira Chaleff, Dr. Joanne Ciulla, Dr. Gene Dixon, Dr. Barbara Kellerman, Dr. Rob Koonce, Dr. Jean Lipman-Blumen, and Dr. Ron Riggio. They were selected based on their unique expertise in the fields of leadership and followership, extensive research in these areas, and professional publications.

In accordance with the right to privacy (protecting the identity of the subject) (Denzin \& Lincoln, 1998), options outlined in the informed consent form provided participants with (a) a preference to have their names revealed for academic and publishing purposes, or (b) full confidentiality of their responses and complete anonymity. All study participants indicated a preference towards disclosing their identities and expert opinions.

The author met with six leadership and followership experts at the $15^{\text {th }}$ International Leadership Association Global Annual Conference in Montreal, Canada, where they were interviewed October 30th through November 2nd, 2013. Each in-depth individual interview session lasted between one and two hours and was audio-taped. One expert was not able to attend the conference, but kindly agreed to a phone interview.

\section{PROCESS OF DATA ANALYSIS}

This study relied on the constructivist approach (Charmaz, 2004) of developing a grounded theory. An open-coding procedure was applied at the initial stages of the study, followed by theoretical, axial, and selective coding (Corbin \& Strauss, 2008). After the substantive, theoretical, and axial coding processes were complete, the author proceeded to identify the theoretical categories. Theoretical sampling process was escorted by constant comparison, a vital companion of grounded theory. As a result of theoretical sampling, three categories were produced:

1. Five themes emerged and appeared inter-linked and logical, all related to the phenomenon of followership and its teachability. 
2. Three of the participants revealed a distinct feature in common: They exhibited a negative attitude either to the term follower or to lists of attributes in general.

3. The respondents' comments in relation to the 12 attributes proposed by Antelo et al. (2010) were summarized into the following groups: "I agree with the attribute," "I highly agree with the attribute," "I suggest that this attribute should be somewhat re-worded or re-defined," and "I will provide an example for this attribute, based on my academic experience."

Data analysis resulted in emergent themes, outliers, and expert opinions regarding the follower attributes proposed by Antelo et al. (2010).

\section{EMERGENT THEMES}

Five emergent themes constitute the findings of this grounded theory. The first and fifth themes emerged naturally, in the process of the conversation. The second, third, and fourth themes emerged as a result of answers to the questions asked during the interview.

Emergent Theme 1: Leadership and followership are an inseparable unity. Experts unanimously concluded that leadership and followership should not be studied in isolation. Every time a discussion on leadership is initiated the only way it can be brought to equilibrium is when the followership component is given equal attention.

Emergent Theme 2: Scarcity of followership classes is explained by a negative stereotype prevalent in the United States. Participants confirm that Western society is enthralled by the leadership phenomenon. Individuals welcome books, courses, and trainings of any sort on leadership, but, on the opposite, resist and cushion themselves with caution and skepticism every time the word follower enters a conversation.

Emergent Theme 3: Follower skills can be taught. When asked whether they thought followership skills can be taught, six out of seven participants had replied positively. The interviewees believe that followership skills can be taught, as supported by Robert Kelley (1992), who affirms that follower skills are "learnable and doable" (p. 129).

Emergent Theme 4: Academic levels that followership should be taught at vary from high school to graduate school. Opinions on the academic levels at which followership classes should be offered included the following responses: (a) at or prior to high school; (b) undergraduate and graduate programs; (c) graduate programs first, followed by undergraduate; (d) should be offered every time a leadership course is offered.

Emergent Theme 5: A leadership-followership class should be offered. Five out of seven participants noted that they would like to see a course combining the elements of both leadership and followership, where equal attention is given to both paradigms. Currently, classes on leadership either omit the follower component in their syllabi or devote a limited time to it.

\section{OUTLIERS OF THE STUDY}

Two out of seven participants, Gene Dixon and Jean Lipman-Blumen, expressed a strong rejection of the terms follower and followership. Barbara Kellerman was skeptical of all lists of characteristics for both leaders and followers, and skeptical about teaching the "how to" approach, giving a preference to "teaching about." These outliers enriched the study as they expanded our understanding of different standpoints that exist but may not be otherwise known.

\section{EXPERT OPINIONS ON THE LIST OF FOLLOWER ATTRIBUTES}

Study participants were asked to express their opinions on the 12 follower attributes proposed by Antelo et al. (2010). Their responses furcated into four categories: (a) agreed that the attribute is important for individuals in the follower role to be developed and exhibited, and, therefore, to be taught; 
(b) agreed that the attribute is highly important for individuals in the follower role; (c) provided suggestions to re-word the definition or a term of an attribute for clarity and appeal to a larger audience; and (d) provided suggestions for additional attributes to be added to the list. Figure 1 presents the following information and ratings: Twelve attributes proposed by Antelo et al. (2010), number of respondents who agreed that the attribute is important for individuals to develop, exhibit in the follower role, and, therefore, to be taught; and number of respondents who agreed that the attribute is highly important to develop, exhibit in the follower role, and, therefore, to be taught.

Table 1 presents the attributes and the number of respondents who suggested that either the definition or the attribute itself should be re-worded to radiate more clarity and appeal to a larger audience. It also presents suggestions for re-wording. Participants suggested other attributes that they thought were critical for individuals to display in the followership role, as presented in Table 2.

\section{FIGURE 1}

\section{PARTICIPANTS' RATING OF THE IMPORTANCE OF FOLLOWER ATTRIBUTES}

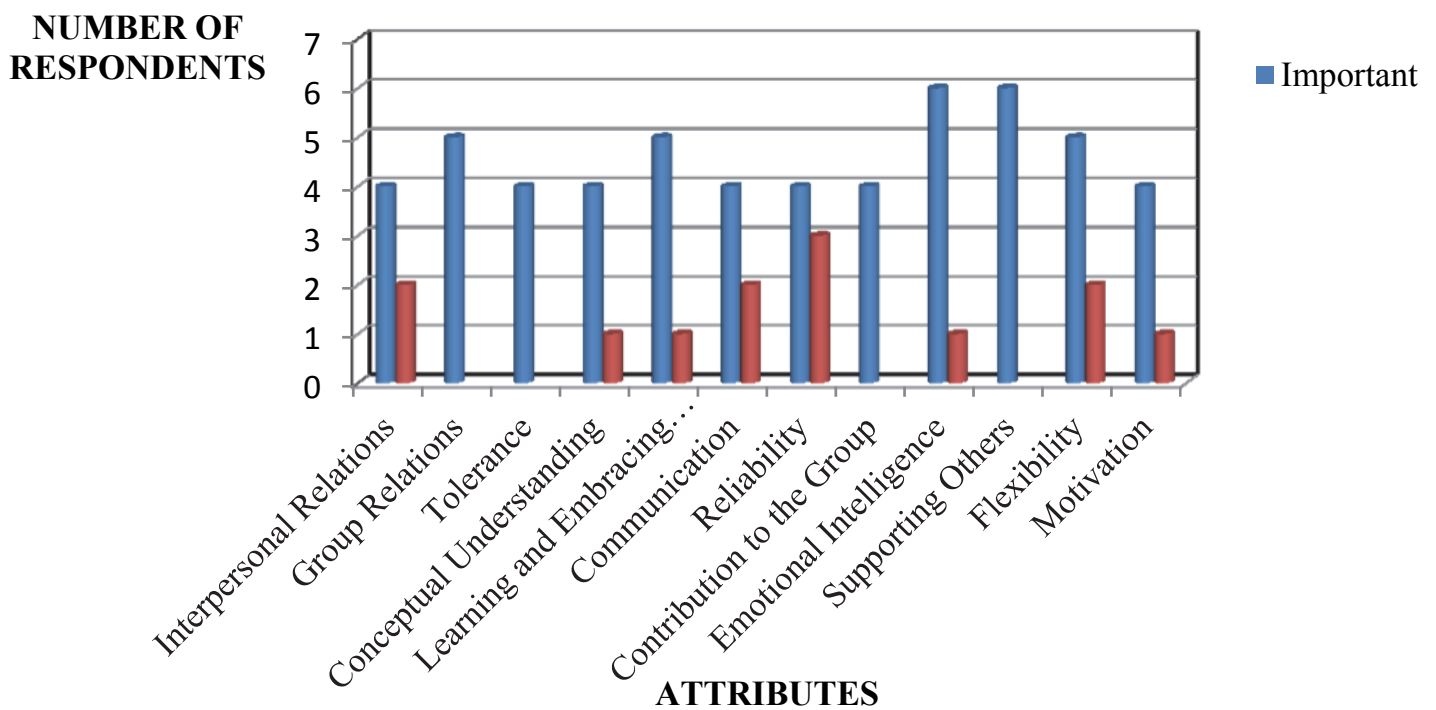


TABLE 1

ATTRIBUTES SUGGESSTEDTO BE RE-WORDED BY PARTICIPANTS

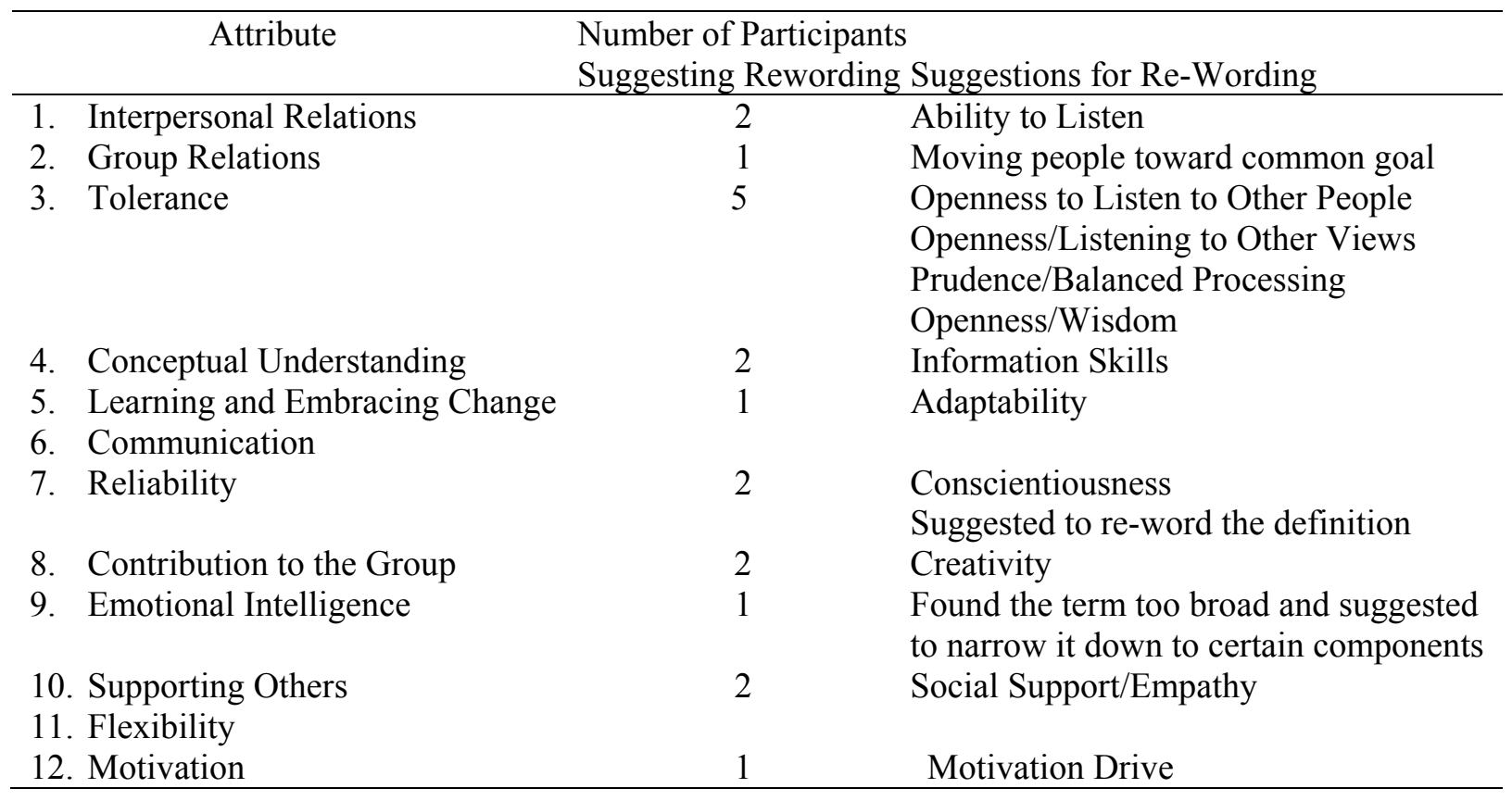

TABLE 2

ADDITIONAL ATTRIBUTES SUGGESTED BY PARTICIPANTS

\begin{tabular}{cc}
\hline Name of the Participant & Suggested Attribute \\
\hline Ira Chaleff & Courage \\
& Good Judgment \\
& Candor \\
& Diplomacy \\
Joanne Ciulla & Ability to Find Knowledge \\
\hline
\end{tabular}

\section{DESCRIPTION OF THE GROUNDED THEORY}

The purpose of this study was to identify the most important characteristics to be exhibited by individuals in the follower role and propose a method of teaching them to become skilled followers. The results of this study are extended as a set of propositions:

1. A Leader-Follower course needs to be developed as any audience consists of leaders and followers and each individual shifts roles in the leadership process.

2. A Leader-Follower course is appropriate at any academic level when a typical leadership course would be offered - starting from high school and beyond post-graduate level in the form of organizational training.

3. Various views need to be taken into account when addressing an audience of the course. Negative stereotype associated with the term follower prevalent in Western culture as well as opposition/rejection of the term should be discussed. Thus, it is recommended to introduce the works of Gardner (1987) and his alternatives to the term such as constituents, partners, co-creators, co-leaders, and other terms, as well as the views of Rost (1991). 
4. The 17 attributes suggested to be taught are the attributes preserved (five of the original attributes), re-worded (seven), and added to the list (five), as presented in Table 3.

The attributes, however, may not be identical for leaders and followers. While some of them are commonly desired characteristics (Hemphill \& Coons, 1950; Stogdill \& Coons, 1957), the other attributes are particular to leaders or followers to a different extent (Antelo et al., 2010; Prilipko et al., 2011).

The 17 follower attributes need to be integrated into the course material and should be undergirded in classical elements of theory so that when a theoretical concept is reviewed, it is approached from the dual standpoint - that of a leader and a follower. Can we enjoy ourselves when we are studying about them, leaders? Would we rather enjoy ourselves in the classroom if we apply the concepts and theories to both leaders and followers, to the situations from the followers' perspective?

\section{CONCLUSION}

This study identified the most important characteristics to be exhibited by individuals in the follower role as perceived by seven followership and leadership experts in the United States. The theoretical framework used for this study was 12 follower attributes proposed by Antelo et al. (2010).

The grounded theory constructed as a result of the study revealed the following:

(a) scarcity of followership courses in academic curricula can be explained by the negative stereotype of the term follower prevalent in the Western society, (b) follower skills can be taught, (c) followership should be taught every time leadership is taught at academic levels ranging from high school to post graduate, and (d) 17 follower attributes were suggested for the purpose of teaching individuals. The identified follower attributes should be integrated into the Leader-Follower course, linked with leadership theories, and approached from the points of view of both leaders and followers. 
TABLE 3

SEVENTEEN ATTRIBUTES SUGGESTED TO BE TAUGHT

\begin{tabular}{|c|c|c|}
\hline Original Attributes & Attributes Re-worded & Attributes Added to the List \\
\hline \multicolumn{3}{|l|}{ 1. Interpersonal } \\
\hline \multicolumn{3}{|l|}{ Relations } \\
\hline \multicolumn{3}{|l|}{ 2. Communication } \\
\hline \multicolumn{3}{|l|}{ 3. Emotional } \\
\hline \multicolumn{3}{|l|}{ Intelligence } \\
\hline \multicolumn{3}{|l|}{ 4. Flexibility } \\
\hline \multicolumn{3}{|l|}{ 5. Motivation } \\
\hline \multirow[t]{2}{*}{ 6. Group Relations } & Group Relations/Moving People & \\
\hline & Toward a Common Goal & \\
\hline \multirow[t]{2}{*}{ 7. Tolerance } & Openness to Others' Views/ & \\
\hline & Listening Skills/Prudence & \\
\hline \multicolumn{3}{|c|}{ Work-related Knowledge } \\
\hline Understanding & & \\
\hline \multicolumn{3}{|c|}{ Embracing Change/ Adaptability } \\
\hline Embracing Change & & \\
\hline \multicolumn{3}{|c|}{ Reliability/Conscientiousness } \\
\hline \multicolumn{3}{|l|}{$\begin{array}{l}\text { 11. Contribution to the } \\
\text { Group }\end{array}$} \\
\hline \multicolumn{3}{|c|}{ Social Support/Empathy } \\
\hline \multicolumn{2}{|l|}{13.} & proposed \\
\hline \multicolumn{2}{|l|}{14.} & Good Judgment \\
\hline \multicolumn{2}{|l|}{15.} & Chaleff \\
\hline \multicolumn{2}{|l|}{16.} & Diplomacy \\
\hline \multicolumn{2}{|l|}{17.} & $\begin{array}{l}\text { Ability to Find Knowledge } \\
\text { (proposed by Joanne Ciulla) }\end{array}$ \\
\hline
\end{tabular}




\section{REFERENCES}

Antelo, A., Henderson, R. L., \& St. Clair, N. (2010). Understanding the process model of leadership: Follower attribute design and assessment. Journal of College Teaching \& Learning, 7(4), 9-14.

Burns, J. M. (1978). Leadership. New York, NY: Harper \& Row.

Chaleff, I. (2009). The courageous follower: Standing up to and for our leaders (3rd ed.). San Francisco, CA: Berrett-Koehler.

Charmaz, K. (2004). Grounded theory. In S. N. Hesse-Biber \& P. Leavy (Eds.), Approaches to qualitative research (pp. 496-521). New York: Oxford University Press.

Corbin, J., \& Strauss, A. (2008). Basics of qualitative research: Techniques and procedures for developing grounded theory (3rd ed.). Thousand Oaks, CA: Sage.

Denzin, N. K., \& Lincoln, Y. S. (1998). Collecting and interpreting qualitative materials, (Eds.). Thousand Oaks, CA: Sage.

Gardner, J. W. (1987). Leaders and followers. Liberal Education, 73(2), 4-6.

Hemphill, J. K., \& Coons, A. E. (1950). Leader behavior description. Columbus, OH: Personnel Research Board, Ohio State University.

Hesse-Biber, S. N., \& Leavy, P. (2006). The practice of qualitative research. Thousand Oaks, CA: Sage.

Kelley, R. E. (1992). The power of followership: How to create leaders people want to follow and followers who lead themselves. New York, NY: Doubleday.

Malakyan, P. G. (2014). Followership in leadership studies: A case of leader-follower trade approach. Journal of Leadership Studies, 7(4), 6-22.

Patton, M. Q., (1990). Qualitative evaluations and research methods (2nd ed.). London, England: Sage.

Prilipko, E. V., Antelo, A., \& Henderson, R. (2011). Rainbow of followers' attributes in a leadership process. International Journal of Management and Information Systems, 15(2), 79-94.

Riggio, R. E., Chaleff, I., \& Lipman-Blumen, J. (2008). The art of followership: How great followers create great leaders and organizations. San Francisco, CA: Jossey-Bass.

Rost, J. C. (1991). Leadership for the Twenty-First Century. Westport, CT: Praeger.

Stogdill, R., \& Coons, A. E. (1957). Leader behavior: Its description and measurement (Eds.). Columbus, $\mathrm{OH}$ : Bureau of Business Research, Ohio State University.

Uhl-Bien, M., Riggio, R., Lowe, K. B., \& Carsten, M. K. (2014). Followership theory: A review and research agenda. The Leadership Quarterly, 25, 83-104. 